\title{
Comparative Analysis of Disparity in Demand for Fresh Fish between Rural and Urban Households in Cameroon
}

\author{
E. Stephanie M. Mvodo',2*, Ngite Prudence Mbulle', Ndive Epeti Likowo ${ }^{1,3}$ \\ ${ }^{1}$ Department of Agricultural Economics and Agribusiness, Faculty of Agriculture and Veterinary Medicine, \\ University of Buea, Buea, Cameroon \\ ${ }^{2}$ Agro-Hub, Agricultural Marketing Platform, Buea, Cameroon \\ ${ }^{3}$ Association for Women Empowerment, Buea, Cameroon \\ Email: *mvodostephanie@gmail.com
}

How to cite this paper: Mvodo, E.S.M., Mbulle, N.P. and Likowo, N.E. (2018) Comparative Analysis of Disparity in Demand for Fresh Fish between Rural and Urban Households in Cameroon. Agricultural Sciences, 9, 1131-1144.

https://doi.org/10.4236/as.2018.99079

Received: December 11, 2017

Accepted: September 15, 2018

Published: September 18, 2018

Copyright $\odot 2018$ by authors and Scientific Research Publishing Inc. This work is licensed under the Creative Commons Attribution International License (CC BY 4.0).

http://creativecommons.org/licenses/by/4.0/

(c) (i) Open Access

\begin{abstract}
The past decades have exhibited changes in the consumption of fresh fish. In developing countries, factors affecting fish consumption are different between urban and rural households. This study comparatively analyses the disparity in demand for fresh fish between rural and urban households in Cameroon. Using random sampling, data on the weekly consumption of fresh fish were collected between April and May 2015; 30 households lived in rural localities while 30 lived in urban areas of Buea Municipality. Consumer's income, the price of fresh fish, family size, gender and age of consumers represented parameters of interest. These were analyzed using the independent sample t-test. Results revealed that the availability, the income level and price affected fish consumption of rural dwellers while price, taste, income and affordability determined the consumption patterns of urban dwellers. The study equally revealed that the higher the price of fresh fish, the higher the demand for its closed substitutes and the higher the size of the household, the higher the quantity demanded. Gender, education and marital status did not affect the quantity demanded; family size and age negatively influenced consumers' decision to buy while consumers' income and price of fresh fish positively influenced consumers' weekly and monthly expenditure on fresh fish. The study proposes that more information be provided to consumers regarding the numerous nutritional benefits of fresh fish for both rural and urban dwellers. Also, policy makers and marketers need to improve the availability of fresh fish in rural and semi-urban settings.
\end{abstract}

\section{Keywords}

Cameroon, Fresh Fish, Rural and Urban Household, Demand 


\section{Introduction}

Fish consumption has undergone major changes in the past four decades. World per capita fish consumption has increased steadily from an average of $9.9 \mathrm{~kg}$ in the $1960 \mathrm{~s}$ to $11.5 \mathrm{~kg}$ in the $1970 \mathrm{~s}, 12.5 \mathrm{~kg}$ in the $1980 \mathrm{~s}, 14.4 \mathrm{~kg}$ in the $1990 \mathrm{~s}, 16.4$ $\mathrm{kg}$ in the 2000s and rising above $20 \mathrm{~kg}$ in 2016 [1]. However, this increase has not been uniform across regions. The global increase in fish consumption tallies with trends in food consumption. In general, per capita food consumption has been rising, and in the past few decades nutritive standards have shown positive long term trends, with worldwide increase in the average global calories supply per person and in the quantity of proteins per person. Globally, fish provides $6.7 \%$ of all protein consumed by humans, as well as offers a rich source of long-chain omega-3 fatty and amino acids, vitamins, calcium, zinc and iron [1]. Fish is one of the healthiest animal sources. Its lack of connective tissues makes it easy to digest. Very efficient in the prevention of cardiovascular diseases, high blood pressure, cholesterol, Alzheimer's disease, and various types of cancer, fish consumption contributes up to $108 \mathrm{kcal}$ per capita per day [2] [3] [4] [5] [6]. While the recommended minimum animal protein consumption rate is $12.5 \mathrm{~kg}$ and the required average protein intake by Food and Agriculture Organization of the United Nations (FAO) is $75 \mathrm{~g} / \mathrm{caput} /$ day [3] [5]. Approximately, $16 \%$ of the animal protein consumed by the world's population is derived from fish [7].

Worldwide, around 57 million people work in fish production, a third of them in aquaculture. Global total capture is 93.4 million tons in 2014 with around 4.6 million vessels of which $90 \%$ are in Asia and Africa [1] [4]. Despite this, many countries continue to face food shortages and nutrient inadequacies [7]. In Africa, Morocco and Senegal are top producers of marine fish, while Uganda, Tanzania and Nigeria are among major fish producing countries of inland waters, with production levels of 407,638; 314,945 and 312,009 tons respectively.

Though Africa is amongst the top fish producers [8], its supply of fish remains alarmingly low. Fish still contributes to food security in many regions of the world providing a valuable supplement for diversified nutritious diets.

In Cameroon, fish is available from both external and domestic productions. Due to high demand (about three million tons), Cameroon imports about 20,000 and 60,000 tons from China and Mauritania respectively, representing an average of $50 \%$ of the volume of imports [9]. In 2015, Over 100 billion FCFA was spent on the importation of 150,000 tons of fish.

Annually, Cameroon produces 176,000 tons with only 1,000 tons originating from aquaculture. The sector currently contributes up to nearly $5 \%$ of Cameroon's Gross Domestic Product (GDP). Total consumption of fish in Cameroon has increased by more than 24,000 metric tons from 104,300 metric tons in the period of 1980-1998 [9]. According to Reference [10], imports of fish in Cameroon decreased to 385.08FCFA billion in 2013 from 3,325.16FCFA billion the previous year. Imports in Cameroon averaged 1,961.39FCFA billion from 2001 until 2013 reaching an all time high of 3,325.16FCFA billion in 2012 and rec- 
orded low of 04.20FCFA billion in 2010. The estimated demand is influenced by socioeconomic and cultural factors both in rural and urban households.

The shift in food preferences is not only occurring in Cameroon. There are major changes throughout the world, towards more diversified diets resulting from emerging socio-demographic factors [5]. These changes come with considerable health consequences; malnutrition (under nutrition and micronutrient deficiencies) mostly in developing countries [11] [12].

At regional, urban and village levels, factors such as, income distribution, poverty, availability and accessibility of fish products as well as preferences influence fish consumption. In many developing countries like Cameroon, fish is mainly for direct human consumption. Though it is consumed in all parts of Cameroon, disparities caused by the aforementioned socioeconomic factors exist between rural and urban households [12].

Some researches recommend the creation of awareness for the environmental sustainability of food consumption patterns, particularly in low and middle income countries [1] [5]. Additional research is needed to study how food preferences and perceptions can improve dietary guidelines [3] [6]. The present research seeks to unveil factors that influence disparities of quantity demanded of fresh fish between rural and urban households in Cameroon.

The research hypotheses that:

H0: There is no significant difference in the quantity demanded for fish by rural and urban households.

H1: There are factors influencing the quantity demanded for fish by rural and urban households.

\section{The Demand of Fresh Fish}

Demand determinants differ according to products. It depicts the relationship between quantity and price, changes in the willingness and, movements along the demand curve; also, changes in consumers' income, prices of substitutes, taste and preference, future expectations, number of potential consumers, changes in levels of investments, advertisement, distribution of income, innovation, consumers attitude, feeling about the good and government policy.

Some authors [12] sustain that important drivers of food access such as household income, food prices, food preferences and socio-political factors (discrimination and gender inequality) need to be considered as well as the quality of diet.

Nationwide, Long term food demand is mostly determined by three strongly interlinked factors: population growth, urbanization, and changes in consumption patterns/lifestyles. An increase in income leads to a higher dietary diversity: individuals tend to consume more high-value products such as meat, fish, milk, fresh fruit and vegetables.

Nutritional behavior is determined by several factors including biology and health status, psychology (attitudes, motives, and emotions), socio-economic 
status, socio-cultural constructs (religion, food traditions) and intra-household allocation of food [7]. Komukama in [7] highlights differences in consumers' perceptions and patterns of selected food groups (meat, chicken, fish, fruits and vegetables) and concludes that these perceptions could be affected by different demographic factors. Dependence on fish is usually higher in coastal than in inland areas. Gender differences, nutrition transition, the role of trade liberalization and trade agreements, government policies, income levels, price and availability, preference and attitudes, lifestyle in relation to income, urbanization, Culture are other factors that need to be taken into consideration.

The demand therefore depends on three main categories of drivers: 1) production (supply) factors, 2) the Market factors, and 3) consumption factors.

\subsection{Factors Affecting Fish Production}

The production of fisheries worldwide is approximately 154 million tons per year, and consumption is 18.5 per capita per year [1] [2]. While estimated fish production in Cameroon stands to about 100,000 tons/year. The country highly depends on imports [13]. The study of fresh fish demand and consumption by both rural and urban households has to investigate the level of national supply and the different supply chains as to know the distribution channels, storage facilities and transportation.

Throughout the centuries fish has been an important component of the population's diet in many parts of the world [6]. Most importantly, its production drivers (conditions, levels, workforce and location) have held crucial roles. Fish can be produced or harvested through fresh water, aquaculture and marine fishing. Fish culture is an important commercial undertaking for both rich and poor countries [14] [15].

Fish disease, high price of inputs, lack of money are some identified fish producer's constraints [15]. Taking this further, [8] and [15] sustain that in Cameroon, one of the factors limiting intensification of livestock production is inadequate information on market demand for specific livestock products. For producers to ensure a steady supply of livestock products to the Cameroonian market, a better understanding of household consumption behavior is needed. Factors driving the balance of international trade have to be considered namely imports and exports. The contribution to national indicators such as employment and GDP should be considered as well.

An important factor in fish production is information [16] [17]. Factors affecting fish farmers' access to production information are; inconsistent visits of extension agents, lack of extension trust and participation of fish farmers in fish farmers' association or society, absence of connectivity and lack of knowledge on how to operate the internet, lack of sufficient capital and poor communication reception. There are also issues beyond control which are climate change and marine survival of migratory fish [16] [18].

Another category of factors affecting fish production are: 1) water quality, 2) 
habitat degradation, 3) upland use, 4) water management with abstraction, 5) stock exploitation, 6) predators, 7) introduced species and 8) marine issues.

It is to be recognized that stock of fish seed, fertilizer and artificial feed, human labor, farm size, age of pond, depth of pond water, and number of ponds owned have considerable impact on fish production [17]. Going further, a FAO report [8] presents temperature, morphometry and catchment geology, drought and water level fluctuations sediments, salinization, pollution and eutrophication, species composition importance of small water bodies as factors affecting the productivity of fish in sub-Saharan Africa.

\subsection{Factors Affecting Fish Marketing}

Market conditions relating to the demand of any commodity are influenced by the price, storage conditions, packaging, the availability and communication. At the national and international levels, food prices play a major role in food and nutrition security [11].

If in urban areas, consumers have a great range of substitutes (cow meat, pork, chicken) options are limited for rural populations. The limited and cheap alternatives are mushrooms, bush meat, termites and snails; essential to provide calories, protein and fat [19]. Some scientists discourage the hunting of bush meat as it raises concerns about security and livelihoods, ecological impacts and health.

Consumers rely on markets for food. In recent years, demand studies particularly in developing countries have focused attention on consumer's demand behavior across different income groups. In Papua New Guinea, structural food demand and income elasticities were different between rural and urban areas. Because rural households consume large parts from their own production than urban households, different model specifications may be required to account for the effect of subsistence consumption on households. The concept of weak separability has been used in many studies to estimate household consumption behavior based on market expenditure data and some revealed that on average prices of fish are the same in urban and rural areas [15].

However, increased fish production has received far higher priority from development agencies than the handling, processing and marketing. Therefore, market studies for aquaculture and fish products in Cameroon are of importance because marketing is a vital function of any business as it may be disastrous to produce any commodity which could not be sold. Highlights of fish marketing situation in Cameroon, sources and prices of fish sold, the marketing channels and stakeholders working to promote fishing activities in the country were examined [13]. Results reveal that, fish sale points are in high population density locations; while areas with high population densities and relatively low wage rates were suitable for aquaculture [13] [20] [21]. Fish farmers located far from

roads with erratic production quantities and quality face high transactions costs. Also, significant on-farm labor and access to inputs is crucial. 
Factors affecting fish marketing are linked to seasonal changes of prices. Market price of fresh fish is affected both at the demand and supply sides. On the supply side, there are seasonality, weather conditions, the quantity and the quality available in the market. On the demand side, we have consumer preferences, the price and price of substitutes, the income, market performance and storage [22] [23] [24] [25].

\subsection{Factors Affecting Fish Consumption}

Fish consumption preferences are affected by individuals' socioeconomic characteristics [2] [3]. It can be extrapolated that consumption of fresh fish in Cameroon is driven by the income level of the households, the taste and food preferences. It is clear that, consumption depends on type, wealth and residence of consumers, most people will prefer fresh fish such as frozen mackerel and chicken over bush meat. The purchasing power of household determines the quantities bought and consumed. Smoked caterpillars, fish and bush meat are cheaper than fresh produces. Chicken, pork and meat are some alternatives to fish; mention needs to be done on taboo of some food, mostly bush meat and pork consumption [20].

At national level, food consumption is variably affected by a whole range of factors including food availability, accessibility and choice, which in turn may be influenced by geography, demography, disposable income, urbanization, globalization, marketing, religion, culture and consumer's attitudes [5]. These play a certain role in the world average consumption of $8.2 \mathrm{~kg}$ per capita per year. Moreover sensory and non-sensory factors affect the frequency and preferences [2].

In recent years, the dramatic increase in food prices, the progressive scarcity of inputs (land and water), the increase in life expectancy in developing countries paired with evolving life-styles and with the spreading of new food-related issues such as obesity, call for a complete revision of food security strategies [5] [12] [26].

There is an increase trend of seafood consumption in both industrial and developing countries. Even freshwater fish consumption has experienced tremendous increase, these recent years [5]. Therefore, recommendations for the increase in fish consumption will have to consider concerns for sustainability of marine stocks. The perceived nutritional value of fish has fostered its consumption [1].

For some food groups, the estimates of expenditure elasticities indicate that, meats and fish, grains and dairy products are luxury products while fruits, vegetables and other foods are necessities [6] [27]. Changes in income influence budget shares for meat and fish implying that an increase in the income levels of households would have a positive effect on decisions to purchase [9].

Some results indicate that fish is a relative necessity in Cameroon and is often substituted for beef and chicken by households whose profiles include low in- 
come levels, large household sizes, middle age and less educated people [9]. While Significant differences in fish consumption were found among age, gender and education groups, as well as between marital statuses [2].

The study [12] addresses the framework of determinants of food and nutrition security at multiple levels of aggregation. At the individual and household level, it makes a distinction between drivers that affect the food and nutrition status, and drivers that affect the stability of this status.

\subsection{Contribution of This Study}

Based on other empirical studies, little was found concerning the comparative analysis of fresh fish consumption between rural and urban settings. This paper is to demonstrate disparities in demand for fresh fish for rural and urban households in that part of the south west region of Cameroon. Reference [27] carried out similar research in KwaZulu, estimating factors that can influence the demand for fresh fish. The present paper will contribute to the existing knowledge.

\section{The Methodology and the Model}

\subsection{The Study Area}

Buea municipality is the study area; located at the foot of Mount Cameroon, in the South West Region of Cameroon. The city is the headquarters of the region, in the Fako division. The climate is cool and humid at higher areas of the division (Buea) and hot in lower areas (Limbe). The city is surrounded by 04 coastal cities: Limbe in South West $(29.4 \mathrm{~km})$, Tiko in the South $(16.6 \mathrm{~km})$, Idenau in the North West $(71.4 \mathrm{~km})$, and Douala in the South East $(71.5 \mathrm{~km})$. Apart from the Atlantic Ocean, there are rivers and streams favorable for fresh water fishing: Mungo, Ombe, Ndongo and Benyo. Fresh water fish varieties are Yenga, Cameroon Telga, Molette, Groupa, Clarias (Mud fish) and Sea fish varieties are Bar Fish, Sea Groupa, Sharks, snake fish, kuta, etc.

\subsection{Empirical Model}

A comparative analysis of households' solid management in rural and urban Ghana was conducted using the Pearson's Chi square test [26]. It compared demographic and socioeconomic variables in rural and urban areas. Multivariate Test, Tests of Between-Subjects Effects, and Pair-Wise Comparisons were also performed to determine whether or not solid waste situations in rural and urban areas are different.

The use of probit analysis to evaluate the effects of individual and socio-economic factors that influence the attitudes of households toward the purchase of beef, chicken, pork and fish in Cameroon proved to be important as well [10]. This study concluded that fish is an inferior good whereas chicken and pork substitute each other and are complementary to beef. Tambi [9] using data from a household consumption survey in Cameroon reported a similar finding that fish is a normal good to low income households and an inferior good to high income 
households. The implication of these results is that a policy to raise household incomes would stimulate market demand for beef and fish but not for chicken and pork of low and middle income households.

For the current study, to implicitly carry out the comparative analysis, independent sample T-test was used. The two set of data samples had equal number of respondents but we choose to assume different variances so that the separate t-test model was used as shown by Equations (1) and (2).

$$
t=\frac{\bar{X}_{1}-\bar{X}_{2}}{\sqrt{\frac{s_{1}^{2}}{n_{1}}+\frac{s_{2}^{2}}{n_{2}}}}
$$

And

$$
d f=\frac{\left[\frac{s_{1}^{2}}{n_{1}}+\frac{s_{2}^{2}}{n_{2}}\right]^{2}}{\left[\frac{s_{1}^{4}}{n_{1}^{2}\left(n_{1}-1\right)}+\frac{s_{2}^{4}}{n_{2}^{2}\left(n_{2}-1\right)}\right]}
$$

where

$\bar{X}_{1}=$ Mean of first sample;

$\bar{X}_{2}=$ Mean of second sample;

$n_{1}=$ Sample size (i.e., number of observations) of first sample;

$n_{2}=$ Sample size (i.e., number of observations) of second sample;

$s_{1}=$ Standard deviation of first sample;

$s_{2}=$ Standard deviation of second sample.

The calculated $t$-value is then compared to the critical $t$-value from the $\mathrm{t}$-distribution table with degrees of freedom.

\subsection{Data and Variables}

During data collection, both male and female headed households were interviewed about the rate, the frequency, the importance, the knowledge of nutritive values of fresh fish and income levels. The considered variables were: monthly fish consumption quantity in kilogram, income of household head and price of fresh fish in FCFA. The size of household was estimated from the number of individuals living in each household. The household head's marital status was dummy variable ( $1=$ married; $0=$ otherwise $)$.

Independent variables were categorical and observations were distinct of each group. Living settings in Buea were firstly classified as urban, semi-urban and rural. Those ranked as semi-urban were excluded; only urban and rural households were considered. The research area has an estimated total population of 360,000 inhabitants from where random sampling was applied and data collected using a semi structured questionnaire. We had 30 urban respondents and 30 rural respondents.

While the present study considered the consumption of all types of fresh fish consumed in the study area, a study on the comparative analysis of fresh and 
dried fish consumption, where only two fish markets were selected, was carried out by reference [14]. This study enables the identification of three possible livelihood strategies to tackle issues and risks of fish consumption namely: 1) risk prevention; 2) risk mitigation; and 3) risk coping.

\section{Findings}

Findings reveal that in both urban and rural households $17.6 \%$ and $23.3 \%$ of consumers are male, showing that the great proportion of fish purchase is done by females. Fresh fish is mostly consumed by young people, maybe due to its cleaning constraint as older people confessed preferring smoked fish or other substitutes; the majority of the urban fish consumers age ranges from 21 to 30 years old while in rural area, 25 consumers were in the range of 31 to 40 years old. In the rural area, $43 \%$ of consumers were married, $51 \%$ single and $6 \%$ widows while only $41.7 \%$ of urban households were headed by females. In urban area more than average ( $55 \%$ of respondents) has a full time job while rural areas respondents were mostly farmers, fishermen and seasonal odd jobbers which depict the seasonability of their financial strength. $96.7 \%$ of urban respondents were Christian while 34 rural dwellers were of Christian faith. More than 28.3\% in urban inhabitants have completed university studies while study level in rural area wasn't significant. The data collected and discussions held reveal that urban households consume salmon (Mackerel) 76.7\%, Bar fish 8.3\%, tilapia 3.3\%, Sardine $6.7 \%$. While rural households mostly consume culture species such as mud fish, tilapias along with bought imported/marine species sardine 53\%, Mackerel $40 \%$ and tilapia $7 \%$.

As for price, in urban centers, those who buy for cheaper price represent $20 \%$, as $25 \%$ buy for taste, $13.3 \%$ for affordability and $35 \%$ for preference. In rural area what mostly motivate the purchase is availability $61 \%$ followed by taste $24 \%$ and the price $15 \%$. As for the rate of purchase, in urban area, $18.3 \%$ of respondents buy when need arises and in rural areas when financial means permit.

In urban areas, most consumers' income fell from 70,000FCFA to more than 150,000FCFA while the minority ranges from 60,000FCFA and below. In the meantime, the average monthly income in rural areas barely got to 40,000FCFA. The rate of demand highly depends on the consumers' level of income. About $76.7 \%$ of the total urban consumer's decision to buy rest on their income levels. In urban areas, $86.6 \%$ will increase their quantities demanded if their income increase while $11.7 \%$ maintain quantity irrespective of income or price. Similarly, $85 \%$ of total population reduces demand as income drops.

The quantity of fish consumed ranges from 0.5 to $4.5 \mathrm{~kg}$ on monthly average for urban dwellers while rural consumption average is $2.3 \mathrm{~kg}$. Rural consumers were very sensitive to their quantity of fresh fish demanded based on income level, as most consumers increase quantity demanded as incomes increase.

A good number of consumers complained about high prices. Nevertheless, they continue buying while others prefer substitutes. Prices range from 500 to 
1,900CFA/Kg; unexpectedly; most consumers tend to pay more for substitutes than fresh fish.

\subsection{Interpretation of Results}

The price coefficient $(-0.989)$ denotes the inverse relationship between quantity demanded and the price. The quantities demanded will decrease if prices increase in accordance with the supply and demand theory. The income and family size coefficients have a direct positive impact on quantities demanded their increase will raise the demand for fresh fish by $42 \%$ and $48 \%$ respectively in rural and urban areas. The calculated t-value for price (38.450) is greater that the tabulated t-value (1.67), this shows the significance of price in quantity demanded. The calculated t-values are: income (1.681), family size (1.789), age (1.800), and gender (2.379). Education (-1.109) is insignificant. We therefore fail to reject the alternative hypothesis and admit that there are disparities in factors influencing the quantity demanded for fish by rural and urban households which are the household income, the price, affordability, taste and preferences.

\subsection{Discussions}

Findings reveal that some parameters are in line with prior expectations while others aren't. It is therefore true that disparities exist in terms of fish consumption selon as we deal with urban or rural communities. In the current situation characterized by worldwide stagnating captures fisheries production, as many fish stocks are fully or over exploited an unavoidably rapid increase in aquaculture production, in particular for high value species and globalization of trade are highly commendable. The Cameroon's fisheries department takes special interest in the number of tons of fresh fish consumed and demanded as to forecast future demand. It has to be noted that while the demand from urban dwellers will be driven by the level of income, the taste and type of varieties proposed, demand from rural localities will be mostly driven by affordability and availability.

It is therefore becoming increasingly important to understand the structure and processes of this sector to guide its development. It even interestingly holds important the recognition of the essential role fish plays in food security and the economy in many developing countries including Cameroon. In line with the 1996 world food summit [27] [28], relevant strategies needs to be put in place to investigate fish stocks exploitation, fish consumption and demand so as to insure sustainable future production, demand and the development of that sector.

There exist some initiatives which aim at improving resilience of food systems and inspiring new policies that can mitigate risks and uncertainties caused by economic and climatic shocks, while providing sustainable economic growth in a context of high and volatile food prices, limited natural resources, changing consumption patterns and lifestyles [11] [29]. 
Support for effective and sustainable actions has to include the identification of critical pathways for technological and institutional changes. Three different levels of changes have to be considered: immediate, underlying and structural changes. There is also a need to look at drivers of food security at every level of aggregation (individual, household, national and international), both in the short and long term, the type of locality should also be considered. In the conceptual framework, food availability, access and utilization determine the state of affairs, referred to as the food and nutrition status of an individual or a household [11] [30] [31] [32] [33]. Results point out that more awareness needs to be created for the environmental sustainability of food consumption patterns, particularly in low and middle income countries. Additional research is needed to examine how these perceptions can improve food based dietary guidelines [6] [30] [34] [35] [36]. One of the most striking trends is change in consumption of meat, meat products, fruits and vegetables. By 2020, the share of developing countries in total world meat consumption will increase. New agricultural policies should consider reduction of environmental effects as well as a shift towards improved public health [7] [37] [38]. Future food policies must consider both agricultural and health sectors, thereby enabling the development of coherent and sustainable policies that will ultimately benefit agriculture, human health and the environment [5] [39] [40].

References [30] and [7] indicate that meat and fish, grains and dairy products are luxury products. Most of the rural populations cannot afford them; they are therefore severely animal protein deficient and consequently malnourished.

Apart from pork, education greatly influences the demand of chicken, beef and fish. It becomes significant to improve the quality and standards of population's education as this will increase the beef and fish purchase [10]. These findings suggest the need for increasing household awareness on nutritional qualities of animal and fish products as a basis to increase consumption. In Cameroon, markets locations are attributed according to the density and importance of quarters or council areas; therefore decision makers need to improve availability and accessibility factors.

\section{Conclusion}

It can be concluded that, demand disparity between rural and urban households is greatly influenced by income levels, price, preferences and family size. The urban centres' dwellers depend on the level of income, the taste and the price of fish species and these determine the level of fish demand. In the contrary, fish demand in rural locality depends on the availability and affordability of consumers living there as their revenue levels are usually meagre and erratic. These clearly display coefficients of income and price with positive signs showing their magnitude of impact and demand disparity. Also, the consumers' decision rest on household preference, taste and affordability. However, consumers do not hesitate to go for a close substitute when the price for fresh fish becomes high. 
That easy shift uncovers the need to work and improves distribution and storages line mostly in rural areas. The study therefore suggests that policies in the sector be adapted considering the location of consumers as disparities exist between them. While urban centres may experience some level of availability, the taste and price drive decisions. Policy implications should therefore integrate all groups and all aspects of the value chain for the development of fish culture in the Southwest Region and Cameroon at large.

\section{Conflicts of Interest}

The authors declare no conflicts of interest regarding the publication of this paper.

\section{References}

[1] FAO (2016) The State of World Fisheries and Aquaculture: Contributing to Food Security and Nutrition for All. Rome, 200 p.

[2] Can, M.F., Gunlu, A. and Can, H.Y. (2015) Fish Consumption Preferences and Factors Influencing It. Food Science and Technology, 35, 339-346. https://doi.org/10.1590/1678-457X.6624

[3] Erdoğan, B.E., Mol, S. and Coşansu, S. (2011) Factors Influencing the Consumption of Seafood in Istanbul, Turkey. Turkish Journal of Fisheries and Aquatic Sciences, 11, 631-639.

[4] Oluwasola, O. and Ige, A.O. (2015) Factors Determining the Profitability of Catfish Production in Ibadan, Oyo State, Nigeria. Sustainable Agriculture Research, 4, 57-65.

[5] Kearney, J. (2010) Review: Food Consumption Trends and Drivers. Philosophical Transactions of the Royal Society B, 365, 2793-2807. https://doi.org/10.1098/rstb.2010.0149

[6] Kudzanayi Gono, R., Muzondiwa, J., Chihanga, I. and Rudo Manhondo, P. (2015) Socio-Economic Factors Affecting the Successful Implementation of Aquaculture Projects in Zimbabwe: A Case Study of Chivi District. Livestock Research for Rural Development, 27, 26-29.

[7] Komukama, A. (2011) A Comparative Analysis of Perceptions on the Consumption of Red Meat, Chicken, Fish, Fruits and Vegetables between European and Non-European Adults: A Case Study of Students in Ghent University. Master's Thesis, Ghent University, Ghent.

[8] FAO (2017) FAO Aquaculture Newsleter (FAN). No. 56.

[9] Tambi, E. (2001) Analysis of Household Attitudes toward the Purchase of Livestock Products and Fish in Cameroon. Agricultural Economics, 26, 135-147. https://doi.org/10.1111/j.1574-0862.2001.tb00059.x

[10] (2017) Fresh Fish in Production and Consumption in Cameroon. http://www.statistics-cameroon.org/manager.php?id=9\&id2=53\&link=6

[11] Cornelsen, L., Alarcon, P., Häsler, B., Amendah, D.D., Ferguson, E., Fèvre, E.M., Grace, D., Salas, P.D. and Rushton, J. (2016) Cross-Sectional Study of Drivers of Animal Source Food Consumption in Low-Income Urban Areas of Nairobi, Kenya. BMC Nutrition, 2, 70. https://doi.org/10.1186/s40795-016-0109-z

[12] Pieters, H., Guariso, A. and Vandeplas, A. (2013) Conceptual Framework for the 
Analysis of the Determinants of Food and Nutrition Security. FOODSECURE Working Paper No. 13.

[13] Achu, C.C. (2009) Fish Marketing in Cameroon: A Case Study of Yaoundé Markets. Conference on International Research on Food Security, Natural Resource Management and Rural Development, University of Hamburg, 6-8 October 2009, 1-4.

[14] Mafuru, M.J. and Marsh, T.L. (2003) An Analysis of Household Food Expenditure Systems in Tanzania. Paper Prepared for Presentation at the Western Agricultural Economics Association Conference, The Denver Adam's Mark Hotel, 12-15 July 2003, 1-23.

[15] Taiwo, I.O., Olopade, O.A. and Ipinmoroti, M.O. (2013) Factors Influencing the Marketing of Fresh Fish in Ogun State, Nigeria. African Journal of Livestock Extension, 43, 871-883.

[16] Islam, M.S. (1987) Factors Affecting Pond Fish Production in Northwest Bangladesh. Bangladesh Journal of Agricultural Economics, X, 87-93.

[17] Damilola, K.A. (2013) Factors Affecting Fish Farmers Access to Production Information in Ogun State, Nigeria. Postgraduate Thesis, Aquaculture and Fisheries Management, Federal University of Agriculture Abeokuta, Abeokuta.

[18] Anonymous (2016) Factors Limiting Fishery Production. http://www.ayrshireriverstrust.org/wp-content/uploads/5\%20Limiting\%20factors\% 20analysis.pdf

[19] Viadero, R.C. (2005) Factors Affecting Fish Growth and Production. Water Encyclopedia, 3, 129-133. https://doi.org/10.1002/047147844X.sw241

[20] Van Vliet, N., Nasi, R., Abernethy, K., Fargeot, C., Kumpel, N., Ndong Obiang, A.M. and Ringuet, S. (2010) The Role of Wildlife for Food Security in Central Africa: A Threat to Biodiversity? Chapter 6. 123-135.

[21] Jagger, P. and Pender, J. (2000) Markets, Marketing and Production Issues for Aquaculture in East Africa: The Case of Uganda. IIFET 2000 Proceedings, Montpellier, France, 13-16 July 2010, 1-10.

[22] Campbell, J.S. (2016) Annex 17-Economic Factors Influencing Development and cooperation in fisheries. Fisheries and Aquaculture Department. FAO Corporate Document Repository.

[23] De Silva, D.A.M. Value Chain of Fish and Fishery Products: Origin, Functions and Application in Developed and Developing Country Markets.

[24] Matiya, G., Wakabayashi, Y. and Takenoushi, N. (2005) Factors Influencing the Prices of Fish in Central Region of Malawi and Its Implications on the Development of Aquaculture in Malawi. Journal of Applied Sciences, 5, 1424-1429.

[25] Matiya, G.G., Kumagai, S. and Kazima, J. (2003) Factors Influencing Prices of Fish in Central Region of Malawi. Aqua-Fish Technical Report, No. 2, 23-25.

[26] Boateng, S., Amoako, P., Odame Appiah, A., Afriyie Poku, D. and Kofi Garsonu, E. (2016) Comparative Analysis of Households Solid Waste Management in Rural and Urban Ghana. Journal of Environmental and Public Health, 2016, Article ID: 5780258. https://doi.org/10.1155/2016/5780258

[27] FAO (2017) Factors Affecting Fish Productivity. http://www.fao.org/docrep/008/v5345e/V5345E07.htm

[28] FAO's Programme for Gender Equality in Agriculture and Rural Development (2009) Bridging the Gap.

[29] Agbola, F.W., Maitra, P. and McLaren, K. (2002) The Analysis of Consumer De- 
mand for Food in South Africa Using an Almost Ideal Demand System: Some Preliminary Results. 46th Annual Conference of Australian Agricultural and Resource Economics Society, Canberra, Australia, 13-15 February 2002, 1-12.

[30] Keiron, A. (2014) A Comparative Analysis of the Nutrition Status, Nutrition Knowledge and Food Frequency of Adolescents Attending an Urban Versus a Peri-Urban School in Hilton, Kwazuly Natal. PhD Thesis, University of Kwazulu Natal, Kwazulu Natal.

[31] Njinkue, D. (1992) Contribution a l'etude de Ia politique alimentaire du Cameroun: le cas des viandes. In: Langham, M.R. and Kamajou, F., Eds., Proceedings of an International Symposium on Agricultural Policy Analysis in Sub-Saharan Africa, University Center of Dschang, Cameroon, 371-398.

[32] Ndabeni, L.L. (2015) An Analysis of Rural-Urban Linkages and Their Implications for Policies that Sustain Development in a Space Continuum.

[33] Seham, D. (2005) An Analysis of Food Consumption Patterns in Egypt. PhD Thesis, Aus dem Institut für Ernährungswirtschaft und Verbrauchslehre, Kiel.

[34] Nkendah, R. (2010) The Informal Cross-Border Trade of Agricultural Commodities between Cameroon and Its CEMAC's Neighbours. Paper for the NSF/AERC/IGC Conference, Mombasa, 4 December 2010, 1-42.

[35] Awotide, B.A. (2012) Poverty and Income Inquality among Fish Farming Household in Oyo State. Agricultural Journal, 7, 111-121.

[36] Manjurul, K. (2006) The Livelihood Impacts of Fishponds Integrated within Farming Systems in Mymensingh District, Bangladesh. PhD Thesis, Aquaculture Systems Group, Institute of Aquaculture, University of Stirling, Scotland, UK.

[37] Lynch, S.G. (1988) Income Distribution, Poverty, and Consumer Preferences in Cameroon. The Cornell Food and Nutrition Policy Program (CFNPP). The Division of Nutritional Sciences, College of Human Ecology, Cornell University, Ithaca.

[38] Dastagiri, M.B (2004) Demand and Supply Projections for Livestock Products in India. Policy Paper, National Centre for Agricultural Economics and Policy Research (ICAR), New Delhi, India.

[39] FAO (2017) World Fish per Capita Consumption. http://www.fao.org/news/story/en/item/421871/icode/

[40] Weatherley, A.H. (2011) Factors Affecting Maximization of Fish Growth. Journal de POffice des Recherches sur les Pêcheries du Canada, 33, 1046-1058. 